\section{Teaching about Genocide: Insights and Advice from Secondary Teachers and Professors, Volume 1}

\author{
Samuel Totten, editor \\ Lanham, MA: Rowman \& Littlefield Publishing, 2018 \\ ( $x i$ + 195 pages, ISBN 978-1-4758-2547-3, \$32.00)
}

\author{
Reviewed By \\ Lisa J. Cleath \\ George Fox University
}

For instructors of theology and religion, it is essential to thoughtfully address conversations

on difficult social justice and ethical topics from multiple angles. Teaching about Genocide offers a collection of twenty-two very readable, short chapters by secondary and university-level teachers. On the whole, the pedagogical frameworks and activities in the book are easy to adapt to bachelor's and master's level courses, either in confessional contexts or beyond. Since each chapter is composed by a different author, their priorities vary; most of the authors clarify their student demographics and particulars of their teaching contexts, recognizing the need for every instructor to adapt any course for their given institution and students. Although it is unlikely to become a classic pedagogical text, the sheer diversity of this volume is its strength.

Across the chapters, two primary questions arise as concerns for the authors: what patterns of individual and collective actions lead to genocide, and how can understanding the phenomenon of genocide form students into reflective and active members of society? Even if one does not teach courses solely on the topic of genocide, these questions lead directly to a number of theological and religious issues, including discussions of human nature, systemic and cross-generational sin, religious social responsibility, and transformation of our world into a place of wholeness and health.

Of the twenty-two chapters, I highlight several that struck me as the most useful. A few chapters focused on classroom activities establishing student knowledge. Chapter 1 starts the book off with a concise and clear description of a cluster activity that assesses the depth of student knowledge via individual and collaborative components. Chapter 11 encourages classes to think about the purpose of defining terms through an anonymous collective activity.

A few chapters detail assignments encouraging students to engage in self-reflection and take social action. Chapter 3 culminates in a list of specific ways in which students can take action in response to what they have learned. Chapter 10 provides tools that facilitate student reflection on their personal reactions to different genocides, so that they might consider why or why not they would be stirred morally or ethically to act in response. Chapter 16 outlines "A Letter-Writing Assignment to Combat Psychic Numbing," which looks to be an effective self-reflective response that may even be sent to individual survivors of violence. As described, this activity has the potential to develop empathetic, pastoral action in student response to injustice while validating survivors' experiences.

Finally, some chapters explore pedagogical approaches to personally challenging topics. Chapter 8 is a very thoughtful discussion of how secondary teachers (and likewise college professors) might teach about sexual violence. This chapter is especially strong in nuancing how online teaching venues and student demographics will influence pedagogical choices for this sensitive but important topic. Chapter 17 features a series of ethical questions that an instructor should consider before implementing simulation or role-play pedagogy.

As a professor of biblical studies, I prioritize planning courses that focus on Christian social justice and ethics. This book catalyzed the creation of my "Social Justice and the Bible" syllabus for this coming academic year, in terms of thinking about outcomes, philosophical frameworks, course schedule and assignments, and specific classroom exercises. I believe that other instructors will also be able to effectively apply the detailed contextual conclusions in this varied volume. 